\title{
Características do solo e das mudas de teca em função da adição de lodo do caleiro. ${ }^{1}$
}

\author{
Cristiane Ramos Vieira ${ }^{2}$; Alexsandro Pereira da Silva ${ }^{3}$; Oscarlina Lúcia dos Santos Weber ${ }^{4}$;osé \\ Fernando Scaramuzza ${ }^{5}$
}

Resumo: Este estudo teve como objetivo avaliar o crescimento de mudas de T. grandis Linnaeus filius. utilizando como substrato orgânico e fonte de nutriente o lodo do caleiro. O experimento foi realizado em casa de vegetação, com os tratamentos: 0,0;30,0;60,0; 90,0;120,0 e 150,0 $\mathrm{Mg} \mathrm{ha}^{-1}$ de lodo de caleiro. Aos 120 dias após a semeadura, foram avaliados: altura das plantas, diâmetro do caule, biomassa das partes aérea e radicular e os atributos químicos do solo. Observaram-se incrementos decrescentes para as características morfológicas avaliadas à medida que se adicionou o resíduo, e este, por consequência, alterou todas as características químicas do solo. O lodo de caleiro nas doses estudadas não foi adequado à produção de mudas de $T$. grandis.

Palavras - chave: Tectona grandis; Resíduo de curtume; Salinidade; Desenvolvimento de mudas.

\section{Characteristics of the soil and the seedlings of teak plants submeted to liming sludge.}

\begin{abstract}
This study aimed to verify to evaluate the growth of $T$. grandis Linnaeus filius seedlings using as organic substrate and source of nutrient, the sludge lime. The experiment was conducted in a nursery using the treatments: $0.0 ; 30.0 ; 60.0$; $90.0 ; 120.0$ and $150.0 \mathrm{Mg} \mathrm{ha}^{-1}$ of sludge lime. At the end of the experiment, were analyzed plant height, diameter, shoot and root dry biomass, and chemical soil. It was observed reduced increments in all morphologic characteristics evaluated as the residue is added, and therefore, changed all the chemical characteristics of the soil. The sludge liming in the doses studied was not adequate for the production of $T$. grandis seedlings.
\end{abstract}

Keywords: Tectona grandis; Tannery waste; Salinity; Seedlings development.

\footnotetext{
${ }^{1}$ Recebido em 19.08.2014 e aceito para publicação como artigo científico em: 26.09.2014.

2 Engenheira Florestal, Mestre em Ciências Florestais e Ambientais, Doutoranda em Agricultura Tropical pela Universidade Federal de Mato Grosso - Faculdade de Agronomia, Medicina Veterinária e Zootecnica. Av. Fernando Corrêa da Costa, $n^{\circ} 2367$ - Bairro Boa Esperança. Cuiabá - MT - 78060-900. E-mail: <cris00986@ hotmail.com>.

${ }^{3}$ Engenheiro Florestal pela Universidade Federal de Mato Grosso. Av. Fernando Corrêa da Costa, no 2367 - Bairro Boa Esperança. Cuiabá - MT - 78060-900. (In memorian).

${ }^{4}$ Engenheira Agrônoma D.Sc., Professora do Departamento de Solos e Engenharia Rural da Universidade Federal de Mato Grosso. Av. Fernando Corrêa da Costa, nº 2367 - Bairro Boa Esperança. Cuiabá - MT - 78060-900. E-mail: <oscsan@uol.com.br>.

${ }^{5}$ Engenheiro Agrônomo D.Sc., Professor do Departamento de Solos e Engenharia Rural da Universidade Federal de Mato Grosso. Av. Fernando Corrêa da Costa, nº 2367 - Bairro Boa Esperança. Cuiabá - MT - 78060-900. E-mail: <jscaramuzza@uol.com.br>.
} 


\section{Introdução}

Devido ao acúmulo de resíduos oriundos da atividade humana nos meios urbano e rural, cresce a necessidade de descarte adequado para resíduos urbanos e industriais, como o lodo de esgoto, o lixo urbano e os resíduos de curtume. O Estado de Mato Grosso possui um grande rebanho bovino, visando, principalmente, a produção da carne. Por isso, frigoríficos se instalaram no estado, e com estes os curtumes, que aproveitam a pele do gado para a produção de couro.

Durante as etapas de processamento da pele geram-se resíduos. O processo de remoção de pelos e do sistema dérmico chama-se caleiro, do qual resulta o lodo do caleiro, cuja característica básica é a alta carga orgânica e inorgânica que pode ter o solo como via de descarte, melhorando suas características de fertilidade pela reciclagem de nutrientes (SILVA, 2009).

Diversos estudos têm comprovado os benefícios do uso dos resíduos de curtume em sistemas agrícolas, principalmente como fonte de nutrientes, porém em sistemas florestais este uso ainda é pouco explorado. Alguns estudos foram realizados por Como Possato (2010) e Gamba (2012) em Eucalyptus spp. e; Tavares et al. (2013) em Schizolobium amazonicum Herb.

As etapas de produção de mudas e o plantio florestal consomem grandes quantidades de fertilizantes minerais. Desta forma, a avaliação e definição do uso de resíduos, como componente em substrato, pode incrementar a produção de mudas, minimizando os custos com fertilizantes.

Segundo Lima (2009), para que o lodo do caleiro seja utilizado como corretivo da acidez do solo, deve-se monitorar o teor de $\mathrm{Na}$, e as culturas a serem plantadas em áreas onde se utilizou o lodo devem ser tolerantes ao mesmo e, exigentes em $\mathrm{Ca}$ e $\mathrm{N}$, devido à concentração desses no lodo de caleiro. Teixeira et al. (2006), verificaram que a adição do lodo de curtume eleva o $\mathrm{pH}$ e os teores de $\mathrm{MO}, \mathrm{Ca}$ e $\mathrm{Na}$ do solo. Podendo ainda, elevar o nível de salinidade do mesmo.
Tectona grandis, vulgarmente conhecida como teca, é uma árvore de grande porte da família Verbenaceae, nativa das florestas tropicais do sudeste asiático, atualmente cultivada nos países tropicais (SILVA, 2009). O Brasil tem grandes áreas plantadas com essa espécie, principalmente no estado de Mato Grosso. Segundo Abraf (2013) as maiores áreas plantadas de $T$. grandis estão nas regiões Norte e Centro-Oeste, representadas pelos estados do Pará, Roraima e Mato Grosso (70\% da produção nacional), os quais apresentaram crescente aumento nos plantios quando comparados aos anos anteriores a 2012. O principal interesse pela espécie está na madeira, muito apreciada pelas suas características de durabilidade, beleza e resistência (MACEDO et al., 2005). Como se trata de produto de exportação garante retornos financeiros consideráveis. No entanto, esse retorno só se concretiza quando se trata de madeira de qualidade. Essa qualidade está ligada ao conhecimento das etapas de produção no viveiro, bem como sua nutrição, seja no viveiro ou no campo.

Diante do exposto, objetivou-se avaliar o desenvolvimento de mudas de Tectona grandis, em casa de vegetação, utilizando como substrato orgânico e fonte de nutrientes o lodo do caleiro.

\section{Material e métodos}

O experimento foi instalado na casa de vegetação da Faculdade de Agronomia, Medicina Veterinária e Zootecnia da Universidade Federal de Mato Grosso, utilizando mudas de $T$. grandis, com $10 \mathrm{~cm}$ de altura, 15 dias após a germinação, obtidas por clonagem de estacas (em tubetes). O solo foi coletado da camada de 0 a $20 \mathrm{~cm}$ de profundidade, de área de mata nativa, localizada no Distrito de São Vicente da Serra, Santo Antônio de Leverger - MT. Após coletado, uma amostra foi retirada e caracterizada química e fisicamente conforme Embrapa (1997) (Tabela $1)$. 
Tabela 1: Caracterização química e física inicial do solo.

Table 1: Initial Chemical and physical characterization of soil.

\begin{tabular}{ccc}
\hline Característica & Solo & Unidade \\
\hline $\mathrm{pH} \mathrm{em} \mathrm{CaCl}_{2}(1: 2,5)$ & 4,4 & $\mathrm{~g} \mathrm{dm}^{-3}$ \\
$\mathrm{MO}$ & 25,5 & \\
$\mathrm{Na}^{+}$ & 2,0 & $\mathrm{mg} \mathrm{dm}^{-3}$ \\
$\mathrm{~K}^{+}$ & 30 & \\
$\mathrm{P}$ & 2,1 & \\
$\mathrm{Ca}^{2+}$ & 0,9 & $\mathrm{cmol}_{\mathrm{c}} \mathrm{dm}^{-3}$ \\
$\mathrm{Mg}^{2+}$ & 0,6 & \\
$\mathrm{Al}^{3+}$ & 0,4 & \\
$\mathrm{H}^{+}$ & 4,9 & \\
$\mathrm{CTC}$ & 6,9 & \\
$\mathrm{SB}$ & 1,6 & \\
$\mathrm{~V}$ & 22,7 & \\
$\mathrm{~m}$ & 21,2 & \\
$\mathrm{Areia}$ & 61,6 & 6,7 \\
$\mathrm{Silte}$ & 31,7 & \\
$\mathrm{Argila}$ & & \\
\hline
\end{tabular}

$\overline{\mathrm{pH}}$ em $\mathrm{CaCl}_{2}$ - relação 1:2,5; MO: matéria orgânica; $\mathrm{P}$ e $\mathrm{K}$ - em Mehlich; $\mathrm{Al}, \mathrm{Ca}^{2+}$ e $\mathrm{Mg}^{2+}$ - em $\mathrm{KCl} 1 \mathrm{~N} ; \mathrm{T}(\mathrm{pH} 7,0)-$ capacidade de troca de cátions a pH 7,0; SB - soma de bases; V\% - saturação por bases, em porcentagem; m\% - saturação por Al, em porcentagem.

O lodo de caleiro foi proveniente de indústria de curtume localizada no Distrito Industrial de Cuiabá-MT. Suas características químicas foram verificadas seguindo metodologia do Ministério de Agricultura, Pecuária e Abastecimento - MAPA (1988) (Tabela 2).

Os clones de $T$. grandis passaram por período de adaptação e rustificação de 30 dias, necessários ao seu fortalecimento. Anteriormente ao transplante das mudas, as sacolas plásticas com capacidade para $5 \mathrm{dm}^{3}$ foram preenchidas com solo e doses crescentes de resíduo de caleiro: 0,$0 ; 30,0 ; 60,0 ; 90,0 ; 12,0$ e $15,0 \mathrm{Mg} \mathrm{ha}^{-1}$. As doses foram calculadas considerando o peso seco do lodo de caleiro e do solo. Totalizando seis tratamentos e quatro repetições (24 parcelas), posteriormente dispostos em delineamento inteiramente casualizado.

A mistura permaneceu em período de incubação de 30 dias. Em seguida, as mudas foram transplantadas para sacolas plásticas, compondo as unidades experimentais, mantidas suspensas em bancadas de madeira, dentro da casa de vegetação até o término do experimento. A irrigação foi realizada diariamente, via manual, mantendo a umidade do solo próximo a $80 \%$ da capacidade de campo até o término do experimento. Sendo que, durante o experimento realizou-se monitoramento diário da umidade $\mathrm{e}$ das condições fitossanitárias. 
Tabela 2: Características químicas do lodo de caleiro.

Table 2: Chemical characterization of sludge liming.

\begin{tabular}{ccc}
\hline Característica & Lodo do caleiro & Unidade \\
\hline $\mathrm{pH}$ em $\mathrm{CaCl}_{2}(1: 2,5)$ & 11,9 & $\mathrm{dS} \mathrm{m}^{-1}$ \\
\hline Condutividade elétrica & 1,79 & \\
\hline Matéria orgânica total & 243,0 & \\
Carbono orgânico & 141,0 & \\
Carbonatos totais & 395,0 & $\mathrm{~g} \mathrm{dm}^{-3}$ \\
Hidróxidos totais & 516,0 & \\
Cloretos totais & 237,0 & \\
$\mathrm{~N}$ total & 1,79 & \\
$\mathrm{Ca}^{2+}$ total & 152,0 & \\
$\mathrm{Mg}^{2+}$ total & 3,2 & \\
$\mathrm{Na}^{+}$total & 7,0 & \\
$\mathrm{~K}^{+}\left(\mathrm{K}_{2} \mathrm{O}\right)$ total & 1,6 & \\
$\mathrm{P}^{\left(\mathrm{P}_{2} \mathrm{O}_{5}\right) \text { total }}$ & 3,8 & \\
$\mathrm{Cr}^{+}$total & 0,04 & \\
\end{tabular}

Aos 120 dias, tempo adequado para o término do desenvolvimento de mudas florestais para posterior plantio em campo, as plantas foram medidas quanto à altura e ao diâmetro do caule na altura de 0,05 $\mathrm{m}$ do solo. Em seguida, foram coletadas, lavadas, seccionadas em parte aérea (caule e folhas) e raiz, acondicionadas em sacos de papel e levadas a secar em estufa a $65^{\circ} \mathrm{C}$ até peso constante. Em seguida, o material foi pesado, obtendo-se assim, a massa seca para cada parte da planta. Coletou-se também, amostras de solo de cada unidade experimental.

Os dados obtidos foram submetidos à análise de variância, e os fatores significativos pelo Teste $\mathrm{F}$ tiveram seus níveis ajustados a equações de regressão, utilizando-se, em todas as análises, o nível de significância de $1 \%$. Sendo que, as variáveis: concentração de $\mathrm{Na}$ e $\mathrm{P}$ foram transformadas em $(y+0,5)^{1 / 2}$ antes de submetidas à análise de regressão, a fim de se obter homogeneidade de variância. Para a análise estatística utilizou-se o aplicativo computacional SISVAR.

\section{Resultados e Discussão}

Observaram-se variações nos atributos químicos do solo após a adição de lodo de caleiro na produção de mudas de $T$. grandis. Percebendo-se que, este resíduo promoveu efeitos corretivos ao solo, ao passo que, elevou a salinidade do meio.

$\mathrm{pH}$

A análise de variância foi significativa a $1 \%$ de probabilidade para a variável $\mathrm{pH}$ em $\mathrm{CaCl}_{2}$, ajuste pela regressão quadrática obteve-se $\mathrm{R}^{2}=$ 0,91 (Figura 1). 


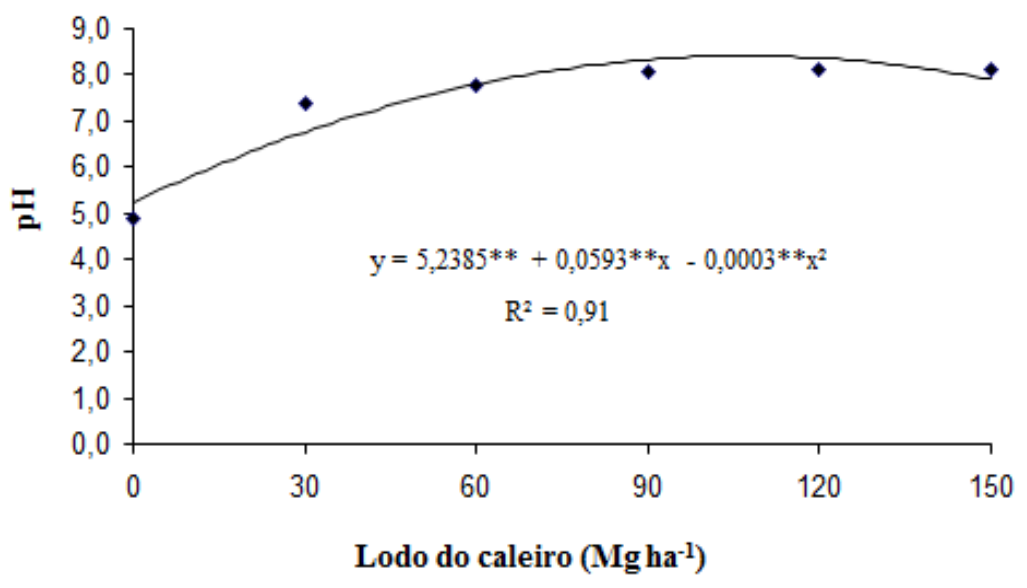

Figura 1: $\mathrm{pH}$ em $\mathrm{CaCl}_{2}$ em função das doses de lodo do caleiro aplicadas ao solo, após 120 dias. **Coeficientes significativos a $1 \%$; *Coeficientes significativos a $5 \%$.

Figure 1: $\mathrm{pH}$ in $\mathrm{CaCl}_{2}$ in function of sludge liming doses applied of the soil, after 120 days. **Significant coefficients to $1 \%$; *Significant coefficients to $5 \%$.

Verificou-se que o $\mathrm{pH}$ variou de 5,23 a 8,16 , o que se deve, provavelmente ao lodo de caleiro, com características inicias de $\mathrm{pH}$ alcalino, já que, o $\mathrm{pH}$ inicial do solo foi considerado ácido. A dose $98,83 \mathrm{Mg} \mathrm{ha}^{-1}$ favoreceu um aumento de 2,93 unidades de $\mathrm{pH}$ em relação a testemunha (dose 0), resultados semelhantes aos obtidos por Ferreira et al. (2003), Souza et al. (2006), Teixeira et al. (2006), Tavares et al. (2013) e Nascimento et al. (2014). Isso evidencia que o lodo de curtume teve efeito na correção de acidez do solo, devido as elevadas concentrações de $\mathrm{CO}_{3}$ e $\mathrm{HCO}_{3}$ presentes no resíduo (NASCIMENTO et al., 2014). A matéria orgânica também pode ter influenciado na elevação do $\mathrm{pH}$ com a adição do lodo de curtume (FAUSTINO et al., 2005), porém em menor intensidade que os carbonatos e hidróxidos.

Condutividade elétrica (CE)

O aumento das doses de lodo de caleiro resultaram em aumento da CE do solo, variando de $0,11 \mathrm{dS} \mathrm{m}^{-1}$ na testemunha a $1,59 \mathrm{dS} \mathrm{m}^{-1}$ na dose 150,0 $\mathrm{Mg} \mathrm{ha}^{-1}$ (Figura 2). Em conformidade com a recomendação de Delarmelina (2012), para espécies florestais, em que, a CE deve estar entre 1,5 a 3,0 dS m $\mathrm{m}^{-1}$. Resultados semelhantes aos observados por Inoue et al. (2010) e Carmo e Lambais (2013). Esse aumento ocorreu devido ao alto teor de $\mathrm{Na}$ do resíduo, elevando a salinidade do solo, e, posteriormente, a CE. No entanto, nas doses estudadas não foi possível estimar a condutividade elétrica máxima permitida para a cultura da $T$. grandis.

Tavares et al. (2013) também atribuíram o aumento da CE ao aumento da concentração de $\mathrm{Na}$ no solo. Teixeira et al. (2011) atribuem ainda, à maior quantidade de gordura no lodo de caleiro. O que pode ser corroborado por Konrad e Castilhos (2002) que observaram os maiores valores de $\mathrm{CE}$ onde o lodo de caleiro foi adicionado em maiores doses, correlacionando com os teores de $\mathrm{Na}$ disponível no solo. $\mathrm{O}$ aumento da $\mathrm{CE}$ do solo prejudica o crescimento das plantas devido ao efeito osmótico, fazendo com que tenham dificuldades na absorção de água e/ou nutrientes.

\section{Sódio}

Ocorreu aumento linear nos teores de $\mathrm{Na}$ no solo com a adição crescente de lodo do caleiro (Figura 3). Costa et al. (2001), Teixeira et al. (2006), Souza et al. (2006), Lima (2009) e Inoue et al. (2010) também verificaram que, em altas doses, o resíduo pode aumentar o nível de salinidade do solo, atribuindo este fato à sua elevada concentração de $\mathrm{N}$. 


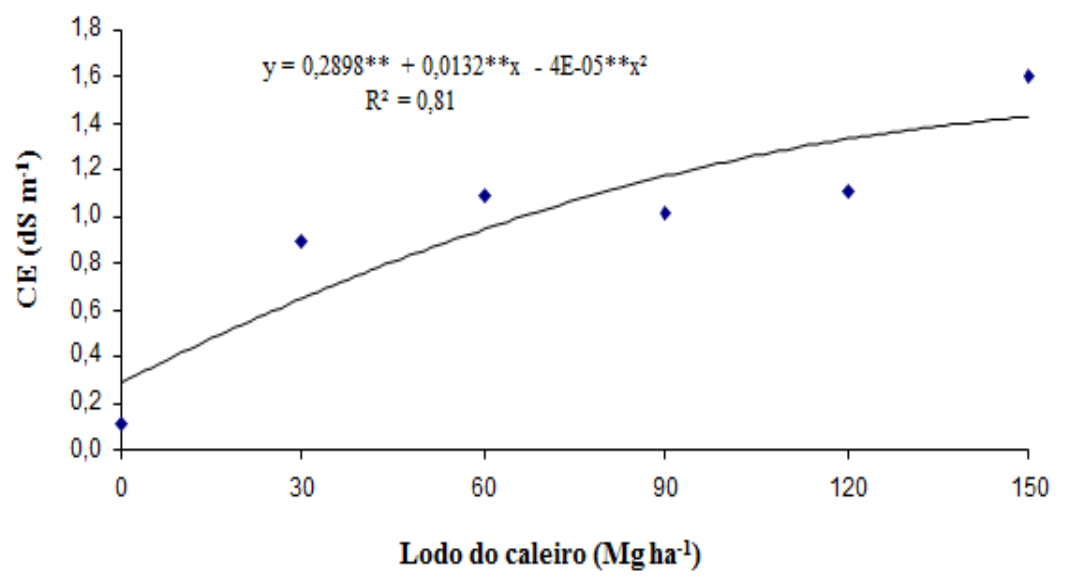

Figura 2: Condutividade elétrica em relação à adição do lodo de caleiro, após 120 dias. **Coeficientes significativos a 1\%; *Coeficientes significativos a $5 \%$.

Figure 2: Electrical conductivity in relation to addition of sludge liming, after 120 days. **Significant coefficients to $1 \%$; *Significant coefficients to $5 \%$.

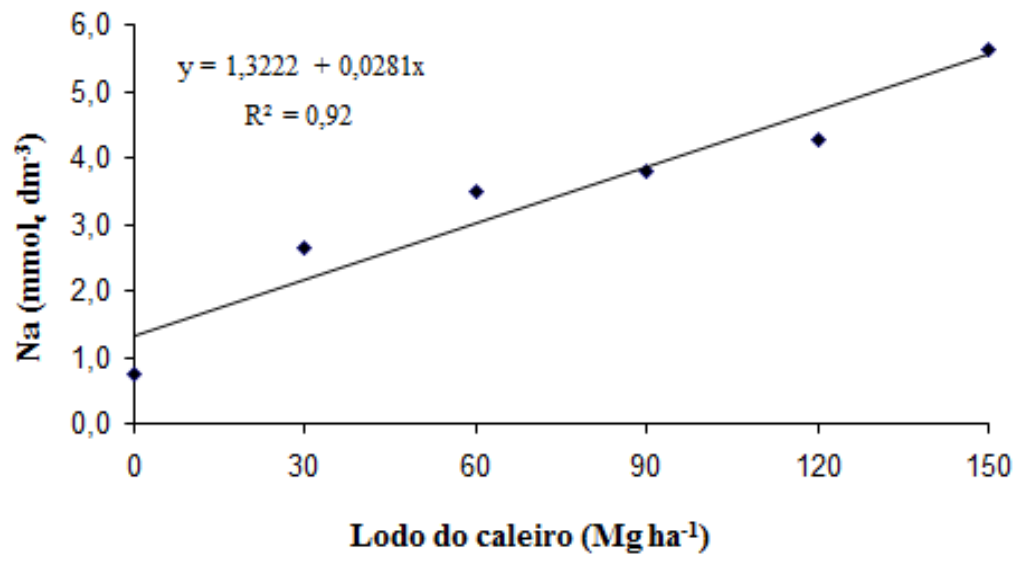

Figura 3: Teor de sódio no solo em relação à adição do lodo do caleiro. Valores de Na transformados, após 120 dias. **Coeficientes significativos a $1 \%$; *Coeficientes significativos a $5 \%$.

Figure 3: Sodium content in the soil in relation to addition of sludge liming. The values were transformed, after 120 days. **Significant coefficients to $1 \%$; *Significant coefficients to $5 \%$.

Portanto, aplicações sucessivas do resíduo no solo implicam em aumentos de $\mathrm{Na}$, cujo acúmulo pode promover impactos negativos sobre o desenvolvimento das culturas e sobre as propriedades físicas do solo (AQUINO NETO e CAMARGO, 2000). Elevando os teores de $\mathrm{Na}$ a níveis acima do recomendado, 4,1 $\mathrm{mmol}_{\mathrm{c}} \mathrm{dm}^{-3}$, segundo Holanda et al. (2007), a partir de 120 $\mathrm{Mg} \mathrm{ha}^{-1}$. Em solos com altos teores de $\mathrm{Na}$, o crescimento das plantas é diretamente limitado, principalmente, em decorrência do efeito do $\mathrm{Na}$ no solo. $\mathrm{O} \mathrm{Na}$ possui a capacidade de expandir e dispersar a argila, provocando o entupimento dos poros, prejudicando a permeabilidade do solo.

\section{Alumínio}

Nesse caso, não foi possível realizar a análise estatística e/ou ajustar a curva, pois, o lodo de caleiro promove efeitos semelhantes ao calcário. Devido aos teores de $\mathrm{Ca}$ presentes no lodo de caleiro (Tabela 2), o elemento satura o solo, reduzindo os teores iniciais de $\mathrm{Al}$ no solo $(0,4$ 
$\mathrm{cmol}_{\mathrm{c}} \mathrm{dm}^{-3}$ ), assim, seu teor é zero.

A concentração de $\mathrm{Al}$ na testemunha foi de $0,375 \mathrm{cmol}_{\mathrm{c}} \mathrm{dm}^{-3}$, completamente neutralizada com o lodo do caleiro. Enquanto que, na dose 30 $\mathrm{Mg} \mathrm{ha}^{-1}$, com $\mathrm{pH} 7,4$, todo o $\mathrm{Al}$ presente no solo foi insolubilizado e precipitado, sendo sua concentração igual a zero para todas as doses, resultados estes atribuídos ao conteúdo de carbonatos e hidróxidos presentes no resíduo. Ferreira et al. (2003), Lima (2009) e Tavares et al. (2013) trabalhando com lodo de curtume obtiveram resultados semelhantes. Garcia et al. (2009) verificaram que, a redução dos valores de Al trocáveis no solo em função das doses de lodo de esgoto ocorreu em função do aumento dos valores do $\mathrm{pH}$.

Cálcio

Os teores de $\mathrm{Ca}$ aumentaram até a dose 104,68 $\mathrm{Mg} \mathrm{ha}^{-1}$, sendo 10,29 $\mathrm{cmol}_{\mathrm{c}} \mathrm{dm}^{-3}$ seu valor máximo (Figura 4), considerado alto teor no solo, apresentando-se satisfatório para a $T$. grandis, exigente neste nutriente (BARROSO et al., 2005). As crescentes concentrações de Ca no solo, observados na Figura 4 podem estar relacionados ao elevado teor do elemento no lodo. Costa et al. (2001), Ferreira et al. (2003), Teixeira et al. (2006), Garcia et al. (2009) e Lima (2009) também observaram resultados semelhantes, atribuindo o aumento do teor de $\mathrm{Ca}$ no solo à elevada concentração deste nutriente no lodo, nas formas de hidróxido, de sulfeto e de carbonato.

No caleiro, a camada epidérmica é eliminada da derme, com os pelos ou a lã, conforme o caso, por meio da destruição das pontes de dissulfeto que unem duas cistinas, principal constituinte da queratina (MOREIRA, 1994), para isso, Ca é utilizado na forma de hidróxido de Ca. Araújo et al. (2008) e Tavares et al. (2013) verificou o efeito direto do lodo de curtume no aumento da concentração de Ca no solo, comprovando seu efeito corretivo.

\section{Fósforo}

Os teores de $\mathrm{P}$ (Figura 5) foram crescentes até a dose de $111,5 \mathrm{Mg} \mathrm{ha}^{-1}$, sendo 3,41 $\mathrm{mg} \mathrm{dm}^{-3}$ seu valor máximo, porém, de baixo teor no solo (BORTOLON e GIANELLO, 2008).

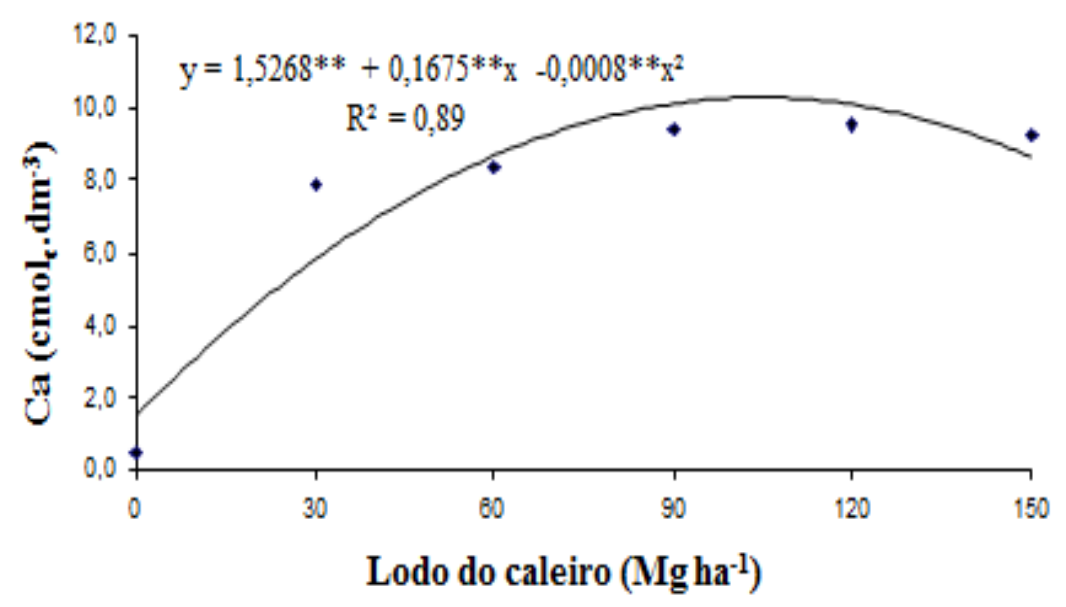

Figura 4: Concentração de cálcio em função das doses do lodo do caleiro, após 120 dias. **Coeficientes significativos a $1 \%$; *Coeficientes significativos a $5 \%$.

Figure 4: Concentration of calcium in function of doses of sludge liming, after 120 days. **Significant coefficients to $1 \%$; *Significant coefficients to $5 \%$. 


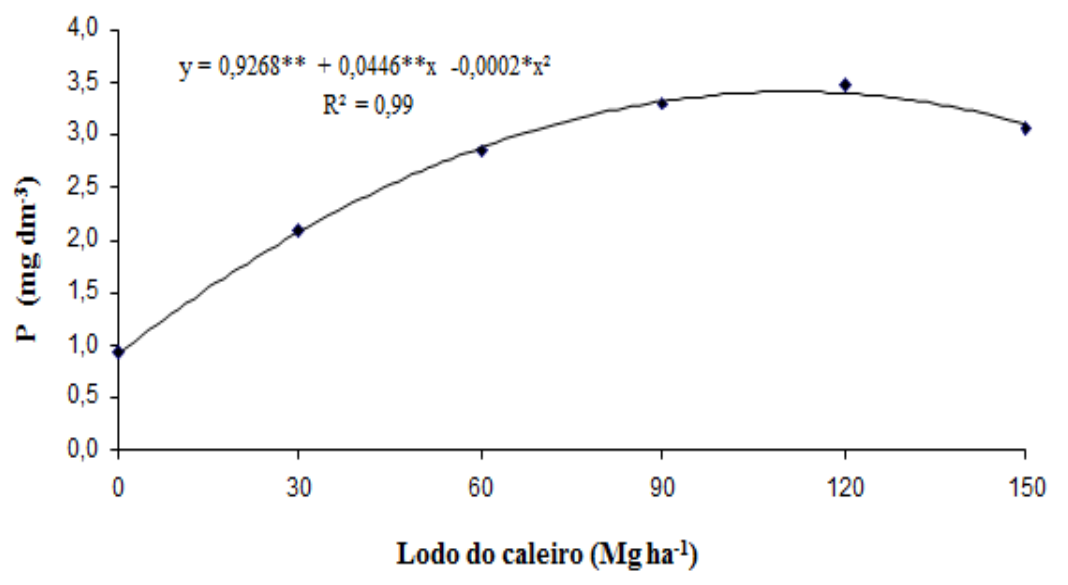

Figura 5: Teores de fósforo disponível no solo em função as doses do lodo do caleiro, após 120 dias. **Coeficientes significativos a $1 \%$; *Coeficientes significativos a $5 \%$.

Figure 5: Content of phosphorus available in the soil in function of sludge liming doses, after 120 days. **Significant coefficients to $1 \%$; *Significant coefficients to $5 \%$.

Araújo et al. (2008), Lima (2009) e Araújo et al. (2009) obtiveram resultados semelhantes. A partir da dose de $111,5 \mathrm{Mg} \mathrm{ha}^{-1}$ observou-se redução na concentração de $\mathrm{P}$, provavelmente devido ao aumento de $\mathrm{pH}$ com a adição do lodo, tornando o solo alcalino. Pois o $\mathrm{P}$ é mais disponível em pH na faixa de 6 a 7 (Malavolta, 1989), com a alcalinização o elemento pode se tornar menos disponível. Segundo Brukman e Brady (1968), em pH acima de 7, pode-se formar fosfatos e complexos de $\mathrm{Ca}$ insolúveis, diminuindo a disponibilidade de $\mathrm{P}$ e de $\mathrm{Ca}$. Portanto, com a elevação do $\mathrm{pH}$ ocorre aumento da solubilidade dos fosfatos de $\mathrm{Fe}$ e $\mathrm{Al}$ e redução da adsorção do ânion fosfato à fase sólida do solo (RAIJ, 1991). Teixeira et al. (2006) observaram redução dos teores de $\mathrm{P}$ disponível no solo com a aplicação do lodo do curtume, que se relacionou com o aumento do $\mathrm{pH}$.

\section{Potássio}

Os teores de $\mathrm{K}$ disponível no solo aumentaram linearmente com as doses de lodo de caleiro (Figura 6), variando de $7,70 \mathrm{mg} \mathrm{dm}^{-3}$ na testemunha a $43,70 \mathrm{mg} \mathrm{dm}^{-3}$ na dose de 150,0 $\mathrm{Mg} \mathrm{ha}^{-1}$. Este aumento na concentração de $\mathrm{K}$ possivelmente deve-se a adição crescente do lodo do caleiro no solo (que possui alta concentração do nutriente), e com a elevação do
$\mathrm{pH}$, se tornou mais disponível, como já relatado por Bonato et al. (1998).

No entanto, após a dose $104,68 \mathrm{Mg} \mathrm{ha}^{-1}$ houve queda nas concentrações de $\mathrm{Ca}$, enquanto que, para o K a tendência foi de elevação. Resultados que podem estar relacionados ao efeito antagônico entre $\mathrm{Ca}$ e K. Esse efeito já foi relatado por Caldeira Junior et al. (2009), ao verificar que, o silicato de $\mathrm{Ca}$ pode reduzir a disponibilidade de $\mathrm{K}$ no solo.

\section{Magnésio}

Para a variável concentração de $\mathrm{Mg}$ não se observou diferenças significativas, como ocorrido em Konrad e Castilhos (2002), Teixeira et al. (2006), Bittencourt et al. (2012) e Tavares et al. (2013). Este fato pode estar relacionado ao baixo teor do nutriente no lodo e/ou ao antagonismo e inibição competitiva entre o Ca e o $\mathrm{Mg}$, uma vez que o excesso de um dos elementos resulta na diminuição da absorção do outro (BARROSO et al., 2005). O excesso do Ca no lodo pode ter interferido na disponibilidade do Mg. Ferreira et al. (2003) obtiveram resultados semelhantes, também atribuindo ao baixo teor de $\mathrm{Mg}$ nos resíduos.

Nesse caso, ocorreu que, por ter maior teor de $\mathrm{Ca}\left(152 \mathrm{~g} \mathrm{dm}^{-3}\right)$ em comparação com o $\mathrm{Mg}$ (3,2 $\mathrm{g} \mathrm{dm}^{-3}$ ), o lodo de caleiro promove a saturação 
dos sítios de troca do solo com $\mathrm{Ca}$, que, por sua vez, desloca o $\mathrm{Mg}$. Portanto, o Mg é deslocado por efeito de massa e assim, não é detectado na análise química. Não sendo possível realizar a análise estatística e/ou o ajuste de curva para esse atributo químico do solo.

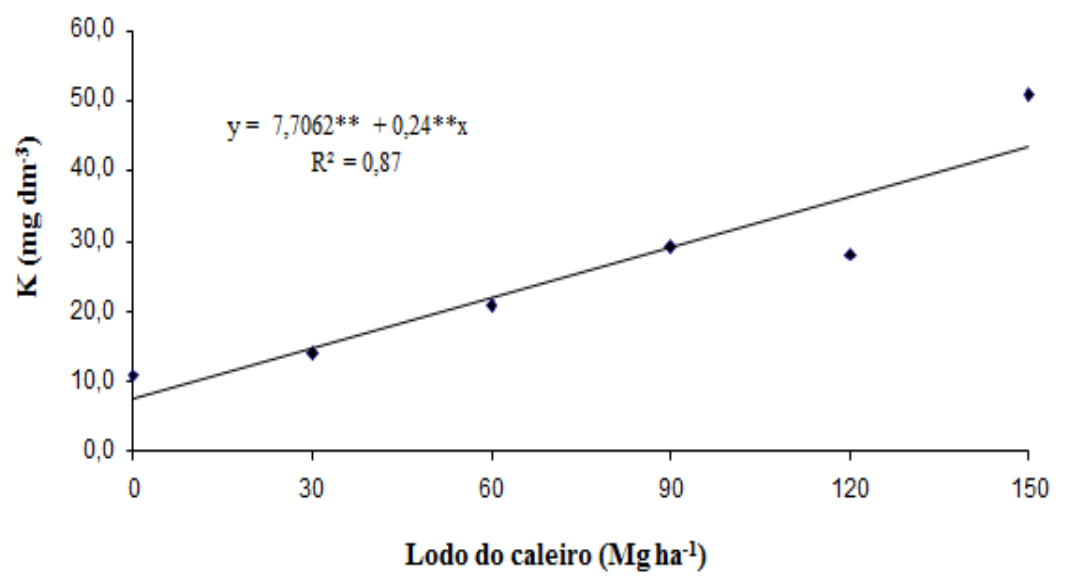

Figura 6: Teores de potássio disponível no solo em função das doses do lodo do caleiro, após 120 dias. **Coeficientes significativos a $1 \% ; *$ Coeficientes significativos a $5 \%$.

Figure 6: Content of potassium available in the soil in function of sludge liming doses, after 120 days. **Significant coefficients to $1 \%$; *Significant coefficients to $5 \%$.

\section{Características morfológicas}

Os crescimentos em altura e em diâmetro reduziram com o aumento das doses de lodo de caleiro (Figura 7), com valor máximo de $18,8 \mathrm{~cm}$ na testemunha e, mínimo de $11 \mathrm{~cm}$ na dose 150 $\mathrm{Mg} \mathrm{ha}^{-1}$ de lodo de caleiro, para o crescimento em altura. E, maior valor, 4,99 $\mathrm{mm}$, na testemunha e o menor, $2,79 \mathrm{~mm}$, com $150 \mathrm{Mg}$ $\mathrm{ha}^{-1}$ de lodo de caleiro no crescimento em diâmetro. Essa redução no crescimento, em altura e em diâmetro, ocasionou redução para as demais características morfológicas, como biomassa.

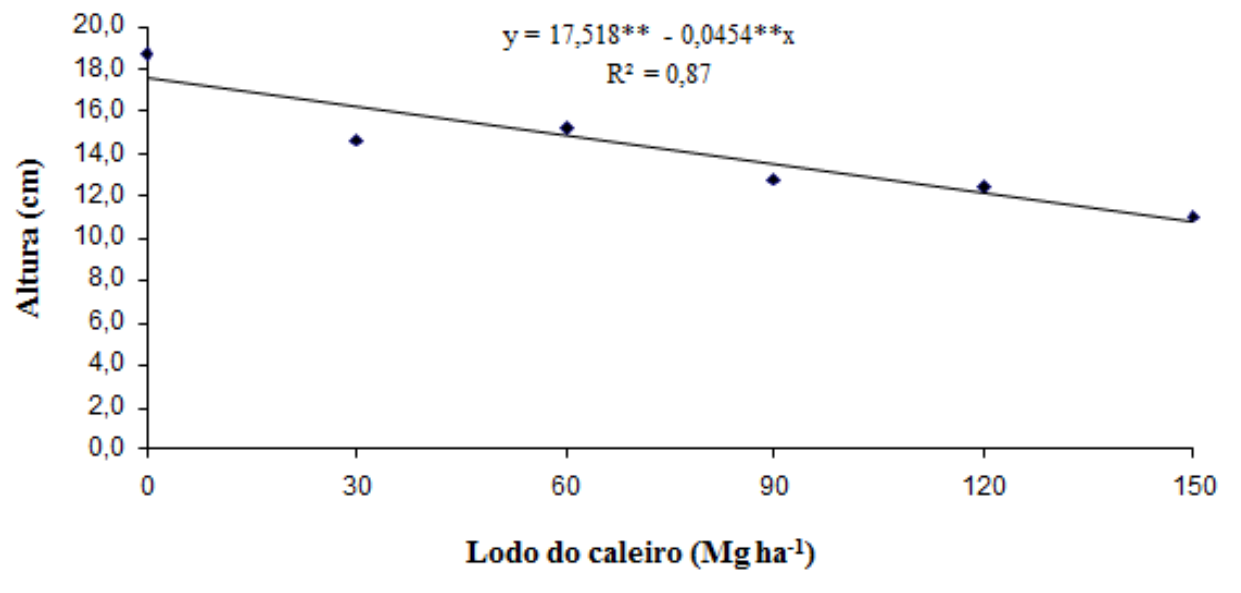




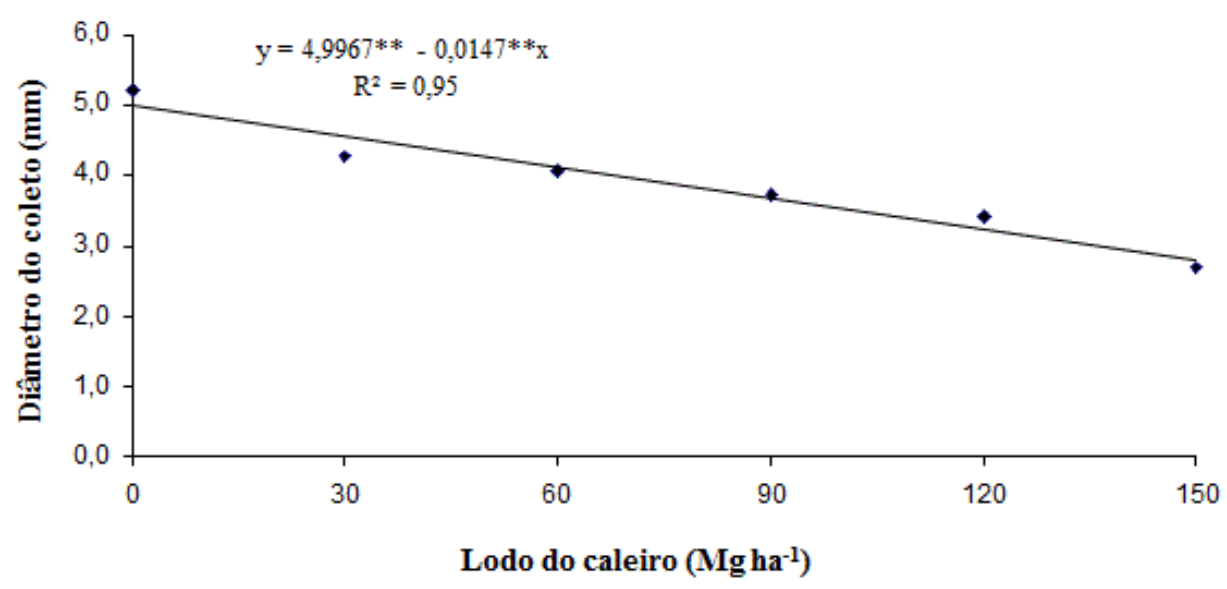

Figura 7: Altura e diâmetro em função das doses do lodo do caleiro, após 120 dias. **Coeficientes significativos a 1\%; *Coeficientes significativos a $5 \%$.

Figure 7: Height and diameter in function of sludge liming doses, after 120 days. **Significant coefficients to $1 \%$; *Significant coefficients to $5 \%$.

Eloi et al. (2007) trabalhando com níveis de salinidade e manejo da fertirrigação sobre o tomateiro, afirmaram que o decréscimo na altura das plantas foi uma consequência do aumento na $\mathrm{CE}$, causada pela salinidade, sugerindo que esta planta é sensível a salinidade. Isso elevou o $\mathrm{pH}$ do solo até determinado nível e, como consequência, causou a redução e/ou aumento na disponibilidade de nutrientes de maneira não adequada para a espécie.

De acordo com Tavares et al. (2013), elevadas concentrações de $\mathrm{Na}$ afetam em maior grau o potencial osmótico do solo limitando o crescimento da planta e a disponibilidade de água a ser consumida, afetando a divisão e o alongamento das células vegetais.

Apesar de Angeli e Stape (2003) afirmarem que a $T$. grandis prefere solos com valores de $\mathrm{pH}$ próximos à neutralidade, neste trabalho os aumentos obtidos nos valores de $\mathrm{pH}$ não foram adequados ao crescimento da espécie, pois causou decréscimo de suas características morfológicas,. O que se deve, provavelmente, às interferências na absorção de nutrientes essenciais.

Gomes et al. (2013) verificaram que, as mudas e Tectona grandis apresentaram maior crescimento em altura em substrato com $60 \%$ de lodo de esgoto misturado a um substrato comercial e, atribuíram esse crescimento aos maiores teores de $\mathrm{N}$ e de $\mathrm{P}$ fornecido pelo substrato orgânico. Porém, trata-se de resíduo diferente do lodo de caleiro e que, portanto, podem conter teores distintos de nutrientes. Isso pode ter contribuído para o menor crescimento das mudas de $T$. grandis ao utilizar o lodo de caleiro, resultado que pode ter sido acentuado devido o efeito salino do mesmo.

Essas características podem indicar que a $T$. grandis não é tolerante à salinidade do solo, pois, não cresce adequadamente nessas condições.

A produção de biomassa também foi menor com as adições do lodo do caleiro (Figura 8). Nesse caso, a biomassa seca do caule decresceu linearmente com o aumento das doses de lodo de caleiro apresentando valores entre 1,58 a $0,78 \mathrm{~g}$ planta $^{-1}$, respectivamente, na testemunha e na dose de $150 \mathrm{Mg} \mathrm{ha}{ }^{-1}$. Esses resultados permitiram inferir que nas doses utilizadas, a produção de biomassa seca do caule diminuiu com o aumento das doses.

A biomassa seca de folhas variou de $3,23 \mathrm{~g}$ planta $^{-1}$ na testemunha a 1,70 g planta $^{-1}$ na dose $150,0 \mathrm{Mg} \mathrm{ha}^{-1}$, decrescendo do modo linear com o aumento das doses de lodo de caleiro. Essa tendência decrescente em relação ao lodo confirma que as doses utilizadas foram muito altas para o solo e para as mudas de $T$. grandis. 


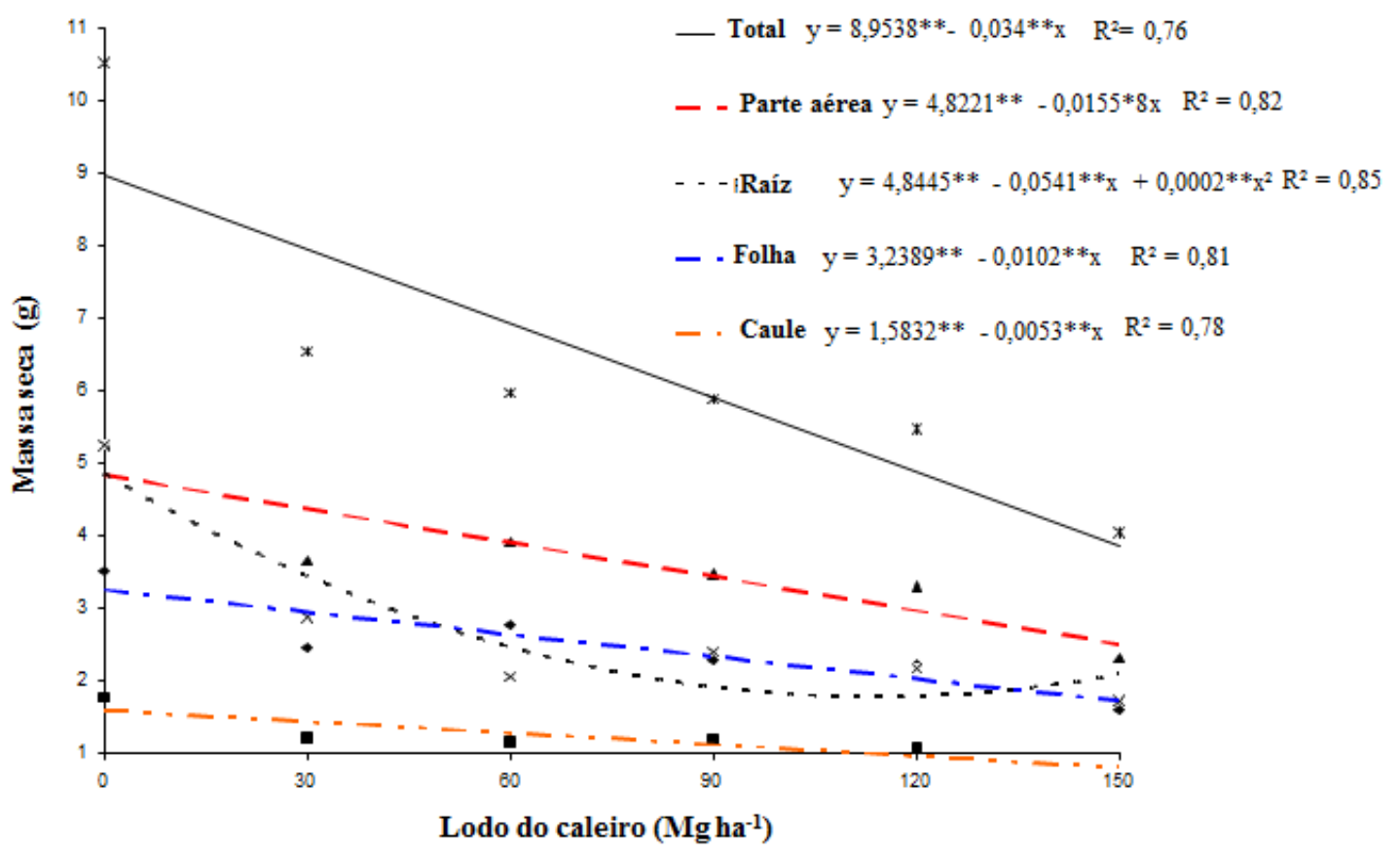

Figura 8 - Massa seca da teca em função das doses do lodo do caleiro, após 120 dias. **Coeficientes significativos a $1 \%$; *Coeficientes significativos a $5 \%$.

Figure 8 - Dry mass of teak in function of sludge liming doses, after 120 days. **Significant coefficients to $1 \%$; $*$ Significant coefficients to $5 \%$.

Portanto, as doses de lodo de caleiro tiveram efeito negativo sobre a biomassa seca da parte aérea, variando de 4,82 a 2,49 $\mathrm{g}$ planta $^{-1}$, respectivamente, na testemunha e na dose de 150 $\mathrm{Mg} \mathrm{ha}^{-1}$. Costa et al. (2001) obtiveram resultados em que o tratamento com a aplicação da maior quantidade de lodo teve o menor rendimento de massa seca, porém o dobro do obtido com a testemunha.

Enquanto que, Daudt et al. (2007) afirmaram que a alta salinidade comprometeu o desenvolvimento das plantas de $T$. patula. $\mathrm{O}$ crescimento foi menor, à medida que o substrato utilizado possuía maior proporção do resíduo, diminuindo o desenvolvimento da parte aérea. Além disso, segundo Brilhante (2006), as plantas podem ter sofrido um estresse gerado pela alta salinidade, provocado pelo $\mathrm{Na}$, que limitou seu crescimento.

A massa seca da raiz decresceu com as doses de lodo de caleiro, ajustando-se por uma quadrática, sendo o menor valor $1,18 \mathrm{~g}_{\text {planta }}{ }^{-1}$ estimado com 135,5 $\mathrm{Mg} \mathrm{ha}^{-1}$. Segundo Larcher (2006) esse decréscimo pode ser devido a um possível estresse salino sofrido pela planta em função dos altos teores de Na no solo.

A produção de massa seca total das mudas de T. grandis decresceu linearmente em relação ao aumento das doses de lodo de caleiro. A maior produção $8,95 \mathrm{~g}$ planta $^{-1}$ foi obtida na testemunha, enquanto a menor, na dose máxima, $150 \mathrm{Mg} \mathrm{ha}^{-1}$.

Portanto, a adição de lodo de caleiro altera as características químicas do solo o que pode dificultar a disponibilidade de nutrientes e, comprometer o crescimento das mudas de $T$. grandis.

\section{Conclusões}

O lodo de caleiro pode ser usado como corretivo da acidez do solo, desde que sejam realizados experimentos buscando a dose apropriada.

Nas doses estudadas, o lodo de caleiro não foi adequado ao crescimento das mudas de Tectona grandis.

Elevadas doses de lodo de caleiro podem salinizar, elevar a condutividade elétrica e 
desequilíbrios nutricionais no solo utilizado na produção de mudas de Tectona grandis.

Mais estudos devem ser realizados a fim de manter o sódio em teores que não prejudiquem a planta e tentar utilizar o lodo em outras espécies.

\section{Referências}

ABRAF. Associação Brasileira de Produtores de Florestas Plantadas. Anuário estatístico ABRAF 2013 - ano base 2012 / ABRAF. Brasília: 2013. 148 p.

ANGELI, A.; STAPE, J. L. Tectona grandis (Teca). Departamento de Ciências Florestais Esalq/Usp, 2003. Disponível em: <http://www.ipef.br/identificacao/ tectonagrandis.asp>. Acesso em: 9 ago. 2009.

ARAUJO, F. F. et al. Desenvolvimento do milho e fertilidade do solo após aplicação de lodo de curtume e fosforita. Revista Brasileira de Engenharia Agrícola e Ambiental, v. 12, n. 5, p. 507-511, 2008.

ARAUJO, F. F.; GIL, F. C.; TIRITAN, C. S. Lodo de esgoto na fertilidade do solo, na nutrição de Brachiaria decumbens e na atividade da desidrogenase. Pesquisa Agropecuária Tropical, v. 39, n. 1, p. 1-6, 2009.

AQUINO NETO, V.; CAMARGO, O. A. Crescimento e acúmulo de crômio em alface cultivada em dois latossolos tratados com $\mathrm{CrCl}_{3}$ e resíduos de curtume. Revista Brasileira de Ciência do Solo, v. 24, n. 5, p. 225-235, 2000.

BARROSO, D. G. et al. Diagnóstico de deficiências de macronutrientes em mudas de teca. Revista Árvore, v. 29, n. 5, p. 671-679, 2005.

BITTENCOURT, S. et al. Aplicação de lodos de estações de tratamentos de água e de tratamento de esgoto em solo degradado. Engenharia Sanitária e Ambiental, v. 17, n. 3, p. 315-324, 2012.
BONATO, C. M. et al. Nutrição mineral de plantas. Maringá: UEM, 1998. 60 p.

BORTOLON, L.; GIANELLO, C. Interpretação de resultados analíticos de fósforo pelos extratores Mehlich-1 e Mehlich-3 em solos do Rio Grande do Sul. Revista Brasileira de Ciência do Solo, v. 32, n. especial, p. 27512756, 2008.

BRILHANTE, J. C. A. Contribuição de solutos orgânicos e inorgânicos no potencial osmótico de folhas de Atriplex nummularia submetidas ao NaCl, seca e peg. 2006. 195 f. Dissertação (Mestrado em Agronomia) - Universidade Federal do Ceará, Fortaleza. 2006.

BRUKMAN, H. O.; BRADY, N. C. Natureza e propriedades dos solos. São Paulo: Freitas Bastos S/A, 1968. 594 p.

CALDEIRA JUNIOR, C. F. et al. Características químicas do solo e crescimento de Astronium fraxinifolium Schott em área degradada adubada com lodo de esgoto e silicato de cálcio. Ceres, v. 56, n. 2, p. 213-218, 2009.

CARMO, J. B.; LAMBAIS, M. R. Transformações do nitrogênio em solos tratados com lodo de esgoto. Revista Brasileira de Agroecologia, v. 8, n. 3, p. 152-162, 2013.

COSTA, C. N. et al. Efeito da adição de lodos de curtume sobre as alterações químicas do solo, rendimento de matéria seca e absorção de nutrientes em soja. Revista Brasileira de Agrociência, v. 7, n. 3, p. 189-191, 2001.

DAUDT, R. S.; GRUSZYNSKI, C.; KAMPF, A. N. Uso de resíduos de couro wet-blue como componente de substrato para plantas. Ciência Rural, v. 37, n. 1, p. 91-96, 2007.

DELARMELINA, W. M. Resíduos na formulação de substratos para produção de mudas de Sesbania virgata (Cav.) Pers. 2012. 59 f. Monografia (Graduação em Engenharia Florestal) -Universidade Federal do Espírito 
Santo, Jerônimo Monteiro, 2012.

ELOI, W. M.; DUARTE, S. N.; SOARES, T. M. Níveis de salinidade e manejo da fertirrigação sobre características do tomateiro cultivado em ambiente protegido. Revista Brasileira de Ciências Agrárias, v. 2, n. 1, p. 83-89, 2007.

EMBRAPA - Empresa Brasileira de Pesquisa Agropecuária. Manual de Métodos de Análise de Solo. 2. ed. Rio de Janeiro: Embrapa - Centro Nacional de Pesquisa de Solos, 1997. 212 p.

FAUSTINO, R. et al. Lodo de esgoto como substrato para produção de mudas de Senna siamea Lam. Revista Brasileira de Engenharia Agrícola e Ambiental, v. 9, [s.n.], p. 278-282, 2005.

FERREIRA, A. et al. Alterações de atributos químicos e biológicos de solo e rendimento de milho e soja pela utilização de resíduos de curtume e carbonífero. Revista Brasileira de Ciência do Solo, v. 27, n. 4, p. 755-763, 2003.

GAMBA, V. S. Avaliação do lodo de curtume como fonte de nutrientes para o crescimento inicial de eucalipto. 2012. 78 f. Dissertação (Mestrado em Ciência Florestal) -Universidade Estadual Paulista "Júlio de Mesquita Filho", Botucatu, 2012.

GARCIA, G. O. et al. Características químicas de um solo degradado após aplicação de lodo de esgoto doméstico. Revista Verde, v. 4, n. 2, p. 1-12, 2009.

GOMES, D. R. et al. Lodo de esgoto como substrato para produção de mudas de Tectona grandis L. Cerne, v. 19, n. 1, p. 123-131, 2013.

HOLANDA, A. C. et al. Desenvolvimento inicial de espécies arbóreas em ambientes degradados por sais. Revista de Biologia e Ciências da Terra, v. 7, n. 1, p. 39-50, 2007.

INOUE, K. R. A. et al. Características do solo submetido a tratamentos com biofertilizantes obtidos na digestão da manipueira. Tecnologia e Ciência Agropecuária, v. 4, n. 2, p. 47-52, 2010.

KONRAD, E. E., CASTILHOS, D. D. Alterações químicas do solo e crescimento do milho decorrentes da adição do lodo de curtume. Revista Brasileira de Ciência do Solo, v. 26, n. 1, p. 257-265, 2002.

LARCHER, W. Ecofisiologia vegetal. São Carlos: Rima, 2006. 550 p.

LIMA, V. S. Atributos de um plintossolo em função do lodo de curtume. 2009. 49 f. Dissertação (Mestrado em Ciências Florestais e Ambientais) - Universidade Federal de Mato Grosso, Cuiabá. 2009.

MACEDO, R. L. G. et al. Desenvolvimento inicial de Tectona grandis L.f. (teca) em diferentes espaçamentos no município de Paracatu, MG. Cerne, v. 11, n. 1, p. 61-69, 2005.

MAPA - Ministério da Agricultura, Pecuária e Abastecimento (Brasil). Laboratório Nacional de Referência Vegetal. Análise de corretivos, fertilizantes e inoculantes: métodos oficiais. Brasília: LANARV, 1988. 104 p.

MOREIRA, M. V. Depilação-caleiro. In: HOINACKI, E.; MOREIRA, M. V.; KIEFER, C. G. Manual básico de processamento do couro. Porto Alegre: SENAI de Artes Gráficas, 1994. $402 \mathrm{p}$.

NASCIMENTO, A. L. et al. Bioscience Journal, v. 30, n. 1, p. 146-153, 2014.

POSSATO, E. L. Uso de lodo de curtume em eucalipto e seu efeito no crescimento de mudas e nos atributos químicos de um Cambissolo. 2010. 48 f. Dissertação (Mestrado em Ciências Florestais e Ambientais) Universidade Federal de Mato Grosso, Cuiabá, 2010.

RAIJ, B. V. Fertilidade do solo e adubação. 
Piracicaba: POTAFOS, 1991. 343 p.

SILVA, A. P. Atributos químicos do solo e características morfológicas de mudas de teca em função da adição de lodo do caleiro. 2009. 54 f. Monografia (Graduação em Engenharia Florestal) - Universidade Federal de Mato Grosso, Cuiabá, 2009.

SOUZA, S. M.; CHAVES, L. H. G.; SOUZA. A. P. Efeito da aplicação de lodo de curtume sobre a condutividade elétrica e reação de solo ácido. Agropecuária Técnica, v. 27, n. 2, p. 77-84, 2006.

TAVARES, L. S. et al. Lodo do curtume e sua influência na produção de mudas de paricá (Schizolobium amazonicum) e nas propriedades químicas do solo. Ciência Florestal, v. 23, n. 3, p. 357-368, 2013.

TEIXEIRA, K. R. G. et al. Efeito da adição de lodo de curtume na fertilidade do solo, nodulação e rendimento de matéria seca do caupi. Ciência Agrotécnica, v. 30, n. 6, p. 10711076, 2006.

TEIXEIRA, S. T. et al. Resíduos de curtume e o aproveitamento agrícola. Revista de Biologia e Ciências da Terra, v. 11, n. 1, p. 138-143, 2011. 